\title{
New Trends and Technologies in Power Electronics and Motor Drives Educa- tion
}

\section{Mr. Yazan Alsmadi, The Ohio State University}

Yazan Alsmadi received the B.S. degree (Summa Cum Laude) in electrical power engineering in 2010 from the Yarmouk University, Jordan, where he ranked 1st in his class. He received Yarmouk University Presidential Award for Academic Distinction in 2009 and Jordan Ministry of Higher Education and Scientific Research Award for Academic Distinction in 2007. He is currently working toward the Ph.D. degree in electrical and computer engineering at The Ohio State University (OSU), Columbus, OH, USA. He was nominated for the Graduate Associate Teaching Award (GATA) at OSU, the university's highest recognition of the exceptional teaching provided by graduate students at Ohio State University. His research interests include integration of renewable energy resources into electric power systems, advanced control theory of distributed power and variable speed systems and development of power electronics systems for renewable energy applications.

Mr. Alsmadi currently serves as a president of the IEEE Graduate Student Body at The Ohio State University (GSB) which is the first graduate student body worldwide. He received the Distinguish Service Award at the 2012 \& 2013 IEEE Columbus Spring Awards Banquets. This is the first time that this award was given to a graduate student. Mr. Alsmadi is a member of the Institute of Electrical and Electronics Engineers (IEEE), American Society of Engineering Education (ASEE), International Council on Large Electric Systems (Cigre), Phi Kappa Phi and Tau Beta Pi.

\section{Kaichien Tsai, The Ohio State University}

Kaichien Tsai received his B.S. degree from The Ohio State University, Columbus in June, 2007. He is currently pursuing Ph.D. degree at The Ohio State University, Columbus since 2008. He was with the Smart Grid team in Texas Instruments for 6 months in 2013. His research interests include motor drive control, high power converter and inverters designs, EMI mitigation techniques, and computer-aided circuit analysis.

\section{Mr. Mark J. Scott, The Ohio State University}

Mark graduated in 2005 from the Ohio State University with a Bachelor's Degree in Electrical and Computer Engineer. Afterwards, he worked as a field engineer installing large industrial automated systems and then as a test engineer validating power electronics designed for automotive applications.

He returned to Ohio State in 2009 to pursue a $\mathrm{Ph}$. D in the field of power electronics. His research is on implementing wide bandgap (WBG) devices, based on gallium nitride $(\mathrm{GaN})$ and silicon carbide $(\mathrm{SiC})$, in new and existing power conversion applications. The focal point of his studies has been on improving power densities of power electronics through the development of high frequency, WBG based switched-capacitor circuits.

\section{Prof. Longya Xu, The Ohio State University}

Prof. Longya Xu joined the Department of Electrical and Computer Engineering, The Ohio State University (OSU), Columbus, in 1990 where he is currently a Professor. He has served as a Consultant to several industrial companies, including Raytheon Company, Boeing, Honeywell, GE Aviation, U.S. Wind Power Company, General Motors, Ford, and Unique Mobility Inc., for various industrial concerns. He is the founding Director of the newly established Center of High Performance Power Electronics, OSU, which is supported by the Ohio Third Frontier Program. His research and teaching interests include the dynamics and optimized design of special electrical machines and power converters for variable-speed systems, the application of advanced control theory and digital signal processors for motion control, and distributed power systems in super-high-speed operations. Dr. Xu served as a Member-at-Large of the IEEE Industry Applications Society (IAS) Executive Board. He has served as the Chair of the Electric 
Machines Committee of the IEEE IAS and an Associate Editor for the IEEE Transactions on Power Electronics. He was the recipient of the First Prize Paper Award from the Industrial Drives Committee of the IEEE IAS in 1990, the Research Initiation Award from the National Science Foundation in 1991 for his work on wind power generation, and the Lumley Research Award from the College of Engineering, OSU, in 1995, 1999, and 2004, for his outstanding research accomplishments.

\section{Prof. Aimeng Wang}




\title{
New Trends and Technologies in Power Electronics and Motor Drives Education
}

\begin{abstract}
This paper presents a new Power Electronics and Motor Drives Laboratory at the Ohio State University (OSU). The laboratory implemented an alternative style of teaching referred to as an "Open Space Laboratory." In this approach, students are provided with all the facilities to do their laboratory work in an openly available work space that can be accessed at a time that is convenient for them. However, due to safety considerations, the implementation at OSU still includes one instructor and at least one lab-monitor to manage potential personnel and equipment safety issues.

This lab course is designed for college seniors and graduate students. It includes a unique set of experiments, with state-of-the-art equipment and software, which combine the traditional power electronics and motor drive circuits with recent innovative energy conversion technologies. The content targets modern industrial applications, including integrating renewable energy resources (wind and solar) into electric power systems.

Most of the required lab hardware was designed and fabricated by instructional lab team members, with additional advanced development kits provided by Texas Instruments (TI). Furthermore, each workstation is furnished with an iPad to facilitate the viewing process.

Discussion starts with a review of the challenges faced by educators in power related fields. Then, the implementation of the Power Electronics and Motor Drives Open Space Laboratory is described in detail along with the hardware employed. The success of the proposed course has been assessed through student enrollment into the course over the last ten years, and by surveying students at the end of the semester.
\end{abstract}

\section{INTRODUCTION}

There is a high demand for qualified engineers in the field of power electronics and motor control (PEMC) as an increasing global population looks to raise its living standards while dealing with greater limitations placed upon fossil fuel based energy infrastructures ${ }^{1-3}$. Educators serving this field must juggle limitations in time and resources, while providing students with an education that will make them top candidates for their careers beyond academia ${ }^{2-13}$. Laboratories are used in this field to supplement the classroom education and reinforce core principles. Educators have three basic methods available to them when they implement their coursework: the "hands-on" approach, remote lab, or a virtual lab". 
The hands-on approach refers to a laboratory where a physical location exists with measurement equipment (e.g. oscilloscope) and devices under test (DUTs). Students go into the lab, usually during fixed hours, and conduct experiments. A common method for implementing this curriculum is to use a building-block approach ${ }^{4-9}$. Complex systems are broken down in to more manageable chunks. Students learn the properties of basic blocks, and begin to integrate these blocks into complex systems.

The University of Minnesota uses what they refer to as the "power pole" structure for their approach $^{4,5}$. This is a reconfigurable two-port network that can create a buck, boost, or buck/boost convertors; it can be cascaded to build inverters, and modified to produce forward or flyback converters ${ }^{4}$. The University of Illinois at Urbana-Champaign has developed what it calls the "blue-box approach"6,7. The difference being that power devices are packaged in stand-alone units (i.e. "blue-boxes") and systems are wired together rather than being connected on a printed circuit board. These approaches alleviate headaches that are often caused by troubleshooting setups based on discrete components.

Other universities have taken to creating remote laboratories ${ }^{10}$. Here students can log into the lab from an offsite location and use a web-based interface to access preconfigured experimental test setups. This approach favors distance-education and allows students more flexibility in their time management ${ }^{10}$. It also gives them the opportunity to repeat experiments; which is often not available in the hands-on approach ${ }^{10}$. However, students are more restricted to the types of experiments they can do.

Virtual laboratories differ from remote labs in that the equipment does not exist; rather it is modelled in software ${ }^{3}$. Some engineering applications are difficult to create labs due to equipment and financial concerns. For example, Oregon State University created a virtual lab to model a chemical vapor deposition (CVD) reactor ${ }^{3}$.

Several trends in this area of education are emerging. First, many universities are designing and building the hardware needed for students to perform their experiments ${ }^{3-11}$. This saves them money and allows them to tailor the lab to their curriculum. A second approach involves working with partners in industry to create laboratories with state of the art equipment and experiments that are relevant to the needs of industry ${ }^{11-13}$. A third trend is that some institutions are turning to advanced simulation systems ${ }^{13-15}$, such as real-time simulation (RTS) laboratories ${ }^{14,15}$. These implementations enable complex systems (e.g. grid-tie power conversion) to be safely modelled in the computer.

The Ohio State University (OSU) switched from a quarter-based to semester-based system in 2012. As part of this effort, the Department of Electrical and Computer Engineering (ECE) updated its curriculum in Power Electronics, Power Systems, and Motor Control to incorporate the approaches listed above. The culmination of this effort was the Power Electronics and Motor Drives Laboratory, which implemented an alternative style of teaching referred to as an Open 
Space Laboratory. The following paper discusses the equipment that was built and the industry collaborations that helped make this lab possible. Additionally, details about the "Open Space" implementation are presented.

The rest of the paper is structured as follows: Section II reviews the challenges faced by educators in power related fields. Section III focuses on the approach being adopted by the ECE department at OSU. The implementation of the Open Space Laboratory is described in detail along with the hardware employed. Section IV contains the assessment of the lab. The paper concludes with closing remarks.

\section{CHALLENGES}

Education in PEMC, like most engineering disciplines, faces many challenges. First, there is a limited amount of time to teach material and as technology progresses, the breadth and complexity of the material increases. Second, effective education in a hands-on environment, which is crucial for power electronics education ${ }^{10}$, requires access to expensive equipment. Third, students need to graduate with a skillset that makes them easily marketable to potential employers ${ }^{3}$. However, with a clever use of technology, some personal innovation and by networking with partners in industry these problems can be solved.

PEMC encompasses several disciplines. Engineers in this area are expected to be good with hardware and software. They need to understand the principles of control, digital signal processing, as well as analog and digital circuitry. Simply put, there are too many complex systems/topologies and not enough time to teach them all. Any course or laboratory serving this area needs to precisely target the topics to be covered and to efficiently implement its pedagogy.

An additional constraint to this field is the cost associated with laboratory equipment. Students need access to oscilloscopes, power supplies, microcontrollers, and hardware (e.g. inverters, converters). Furthermore, it is nearly impossible for students to experiment in areas related to power transmission and distribution due to both the expense of this equipment and the concerns related to safety.

For most students, a degree in engineering is a stepping stone to a career in an industrial setting. Therefore, students need to graduate with the knowledge necessary to thrive in industry ${ }^{3}$. This is not limited to a solid understanding of engineering fundamentals, but needs to be extended further to hands-on experience with tools employed in industry.

\section{OVERVIEW OF THE ECE PROGRAM AT OSU}

The Power Electronics and Motor Drives Laboratory at OSU is designed for college seniors and first year graduate students. It includes a unique set of experiments with state-of-the-art equipment and software. It combines the traditional power electronics and motor drives circuits 
with emerging energy conversion technologies. The content targets modern industrial applications, including integrating renewable energy resources (e.g. wind, solar) into electric power systems. Table I shows the prerequisites for the course.

Although knowledge of sampling theory, digital signal processing (DSP), electromagnetics and control are helpful, this background is not required to enroll in the laboratory because it is briefly reviewed during the course lectures on an as needed basis. Meanwhile, graduate students at all levels, M.S. or Ph.D., are permitted to take this course without any prerequisites. This is based on the fact that many OSU graduate students have already taken similar courses during their undergraduate career.

\section{A. Objectives of the Power Electronics and Motor Drives Laboratory}

The objective of the Power Electronics and Motor Drives Laboratory is for students to become proficient in laboratory analysis and evaluation of power electronics circuits, as well as understand the basics for applying digital signal processor (DSP) in power electronics and motor drive control.

\section{B. Previous Approach and Associated Challenges}

The traditional approach to teaching this lab was to have instructors give a full lecture before class. Students then follow a set of steps provided in the lab manual to complete various tasks for the assigned lab report. This method was found to be inefficient. First, students felt that lab times were too long and it was hard to maintain their attention. Also, due to the complex hardware and software configurations required to perform the experiments, students with limited background in power electronics forget important details. This required the instructors to be more involved in the experiments to troubleshoot device malfunctions and prevent equipment damage.

The previous implementation faced several challenges. This lab needed to accommodate more students since demand has increased for power electronics and motor drive education. However, due to safety concerns, the class size was restricted in the past. Enrollment was also limited because equipment, such as experimental kits, oscilloscopes, function generator, and power supply, were in short supply. Generally, power electronics involves higher voltage and current; therefore, improper power, or probe connections can cause permanent damage to electronic

components. In the past, a significant amount of time was spent debugging damaged boards and replacing defected devices. 
Table 1: Prerequisites for ECE 5027 - Power Electronics and Motor Drives Laboratory

\begin{tabular}{|c|c|c|}
\hline Course & Students & Topics Covered \\
\hline $\begin{array}{l}\text { ECE 3040: } \\
\text { Sustainable Energy \& } \\
\text { Power Systems I } \\
\text { core course } \\
3 \text { credit hours }\end{array}$ & Undergraduate & $\begin{array}{l}\text { - Introduction to electrical energy systems: } \\
\text { history, current trends } \\
\text { - } \text { Renewable and non-renewable sources } \\
\text { - } \text { Rotating machines and their operation } \\
\text { - Smart grid initiatives }\end{array}$ \\
\hline $\begin{array}{l}\text { ECE 3047: } \\
\text { Sustainable Energy and } \\
\text { Energy Conversion Lab } \\
\text { core course } \\
1 \text { credit hour }\end{array}$ & Undergraduate & $\begin{array}{l}\text { Basics of energy conversion processes for } \\
\text { electrical energy supply systems utilizing } \\
\text { conventional rotating machines } \\
\text { - Hardware-in-the-loop simulation system for } \\
\text { sustainable energy systems }\end{array}$ \\
\hline $\begin{array}{l}\text { ECE 5025: } \\
\text { Power Electronics I } \\
\text { technical elective course } \\
3 \text { credit hours }\end{array}$ & $\begin{array}{l}\text { Undergraduate } \\
\text { Graduate }\end{array}$ & $\begin{array}{l}\text { - Introduction to power electronic conversion } \\
\text { principles. } \\
\text { - Design, control and measurement principles } \\
\text { and techniques of the power electronics } \\
\text { subject. }\end{array}$ \\
\hline
\end{tabular}

\section{Open Space Definition}

The "Open Space" approach was introduced to solve the issues mentioned above. The goal is to effectively teach more students with limited time and test equipment. Ideally, an "Open Space Laboratory" would allow students to walk into the lab anytime during university business hours and perform experiments without the presence of an instructor. Since students are not attending regular lab session, bottlenecks due to a lack of equipment occur less frequently. However, due to safety considerations, the implementation at OSU still includes one instructor and at least one lab-monitor to manage potential personal and equipment safety issues. Although, this approach has enabled OSU to increase the number of students enrolled in the course.

\section{Open Space Implementation}

The instructor records the lecture and test setup process for students to watch before the lab. The videos are uploaded online so that students can watch them directly on iPads, computers, or smart phones anytime. This also allows the flexibility to review parts of the lecture during the lab session. Detailed lab manuals specifying step by step procedures for connecting wires and configuring software are required. Multiple check points are inserted in the lab manual for 
monitoring the student's progress through the experiment. Some typical lab monitor check points are listed below:

1. Please explain the safety requirements of this lab to the lab monitor.

2. Please show your lab monitor the location of DC bus inputs, control signal inputs, test points for $\mathrm{V}_{\mathrm{GS}}, \mathrm{V}_{\mathrm{DS}}$, IL, etc.

3. Please show the lab monitor the oscilloscope channel setup and connections.

4. Please explain the test waveform.

5. Please compare the measured and calculated test results with the lab monitor.

These check points are designed to verify that students have the experiment setup correctly and whether they are getting the right measurements for some of the "key" parameters of the circuit such as input voltage, output load, switch frequency, etc. The video only provides the necessary skills and hints for making the required measurements in each task. This forces students to think on their own to obtain the necessary data so that they can answer the questions at the end of each experiment.

Once a check point is reached, students need the approval of the instructor before proceeding on to the next task. The instructor first verifies that students have set up the experiment correctly, and second, that they can answer the corresponding questions required for completion of the check point. Questions at each check point are designed to make sure that the students truly understand the material and are heading in the right direction. Therefore, it is important to have some questions related to experimental results and wiring before powering up the experiment. However, too many checkpoints must be avoided in order to keep the lab running efficiently.

The experimental results rarely match with the theoretical calculations due to the non-ideal nature of the test setup. Students are also asked to compare both results and be able to understand where the differences are coming from. Since we assume that not all students have the same lab experience, the lab is designed to allow students to get familiar with equipment usage (oscilloscope, function generator, meter, programming software environment, etc.) by completing different tasks in each lab. As the lab progresses, less operation details will be provided and the procedure of the lab focuses on using the tools to observe the test results and answer questions for the lab report.

The type of questions asked at the end of each assignment guide students towards identifying mismatches between ideal and theoretical calculation. They are expected to know the source of these anomalies and how to mitigate them. This information must be addressed in the lab report along with experimental waveforms, detailed calculations, and an explanation of the theory. In the end, the most important thing is to allow students to understand and be able to apply what they learned in the text book. Examples include: 
1. Why is the measured output voltage different from theoretical calculation? Please provide detailed explanation and proof.

2. How did the peak to peak current change as switching frequency increases?

3. What are the advantages and disadvantages of using higher switching frequencies?

E. Lab Curriculum

The lab begins with giving students an introduction to the Open Space structure of the lab including course policies, grading, etc. After which, students are assigned different tasks that familiarize them with the oscilloscope, function generator, power supply and digital multimeter. Upon refreshing the basics, a lab sequence that focuses on the topic of DC/DC converters begins. This material is covered in three separate sessions: 1) Buck, 2) Boost, and 3) Buck-Boost. Students learn the concept of switching speed, switching frequency, duty cycle, and power losses across switching devices in these labs. Each lab is structured so that it builds upon material in the previous labs. And, labs are designed so that students develop good habits for performing experiments in a laboratory environment.

The concepts of DSP programming are taught next. Two experimental kits from Texas Instruments (TI), TMDSSOLARCEXPKIT and TMDS2MTRPFCKIT, are used for the remaining labs. The first kit is a single phase DC/AC inverter and the second is a three-phase inverter. One lab session is dedicated to DSP programming. Students learn to use Code Composer Studio to establish the connection between computer and DSP through an on-board emulator. A program is compiled and downloaded that teaches students how to alter variables so that the blinking speed and intensity of a light bulb can be adjusted. This serves as a stepping stone for learning about concepts related to variable voltage and frequency control. The following section uses a single phase inverter to explore concepts related to interrupt loops, ADC conditioning circuitry, and unipolar PWM control.

The next four sections study three phase inverters. For these experiments, the inverter is connected to a brushless DC (BLDC) motor which is used for teaching motor drive systems. With this platform, students have the chance to explore the concept of space vector pulse width modulation (SVPWM), PI controllers, and open/close rotor position loop. The performance difference with rotor position feedback is fully illustrated in the experiment.

\section{F. Experimental Kits}

Most of the DC to DC converters available in the market are compact in size and have limited access to device measurements. The enriched features in these commercial products also make them too expensive for educational purposes. Therefore, OSU developed Buck, Boost and Buckboost converter boards to create a "student proof" design and with minimal cost. Figure 1 shows the Buck converter board that has been designed for the power electronic lab. A diode is connected in series with the DC bus input and control signal input to protect against reverse 
polarity. A transient-voltage-suppression (TVS) diode is applied at the control circuit power supply to prevent over voltage. Hall-effect current sensors are implemented to measure the current through the inductor and the MOSFET. These types of sensors provide the required isolation when measuring voltage and current at the same time. All voltage and current signals (VDS, $V_{G S}, V_{\text {IN }}$, Vout, VDIode, IL, and ID) are measured at test points located along the side of the boards.

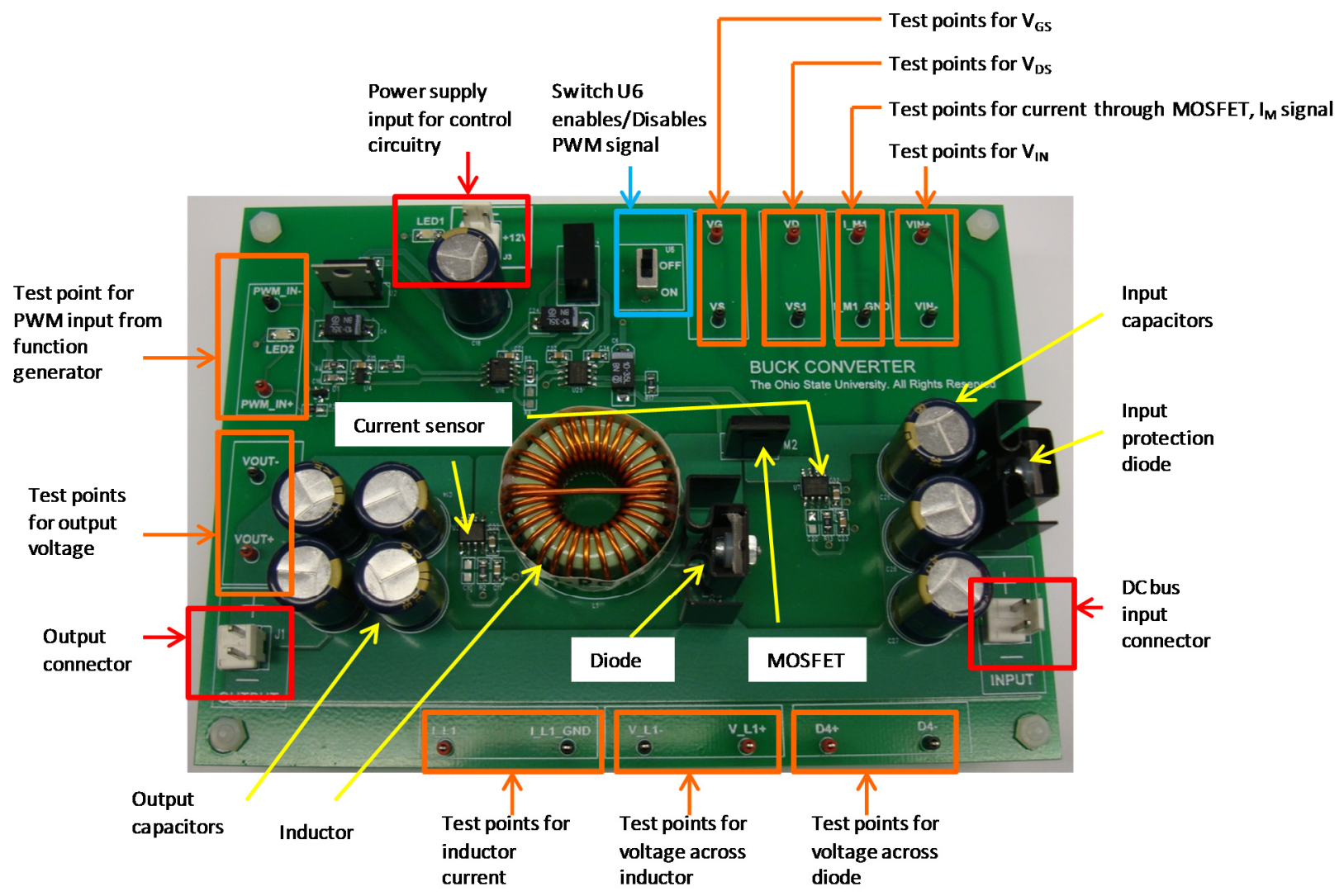

Figure 1: Buck converter made by OSU

TI has provided OSU with many experimental kits that include DSP with up-to-date control algorithms. These kits are configured into different circuit topologies. Figure 2 shows the TMDS2MTRPFCKIT motor kit selected in the lab for teaching the motor drive system. The kit contains an on-board emulator for quick access between computer and the DSP. It also includes two sets of three phase inverter modules, current and voltage sensing circuits, and all the axillary power supplies required for normal operation. Figure 3 is a homemade three phase LED load with air core coils. A compass can be inserted in the center of the coils and used to demonstrate rotating magnetic flux field to the students. By changing the magnitude of the decoupled $\mathrm{V}_{\mathrm{d}}$ and $\mathrm{V}_{\mathrm{q}}$, students will be able to see changes of field strength through the needle and LED. The rotating field effect can be observed by changing the angle from 0 to 360 degree. The rotation 
speed can also be verified through measuring the number of turns and compare it with the input command.

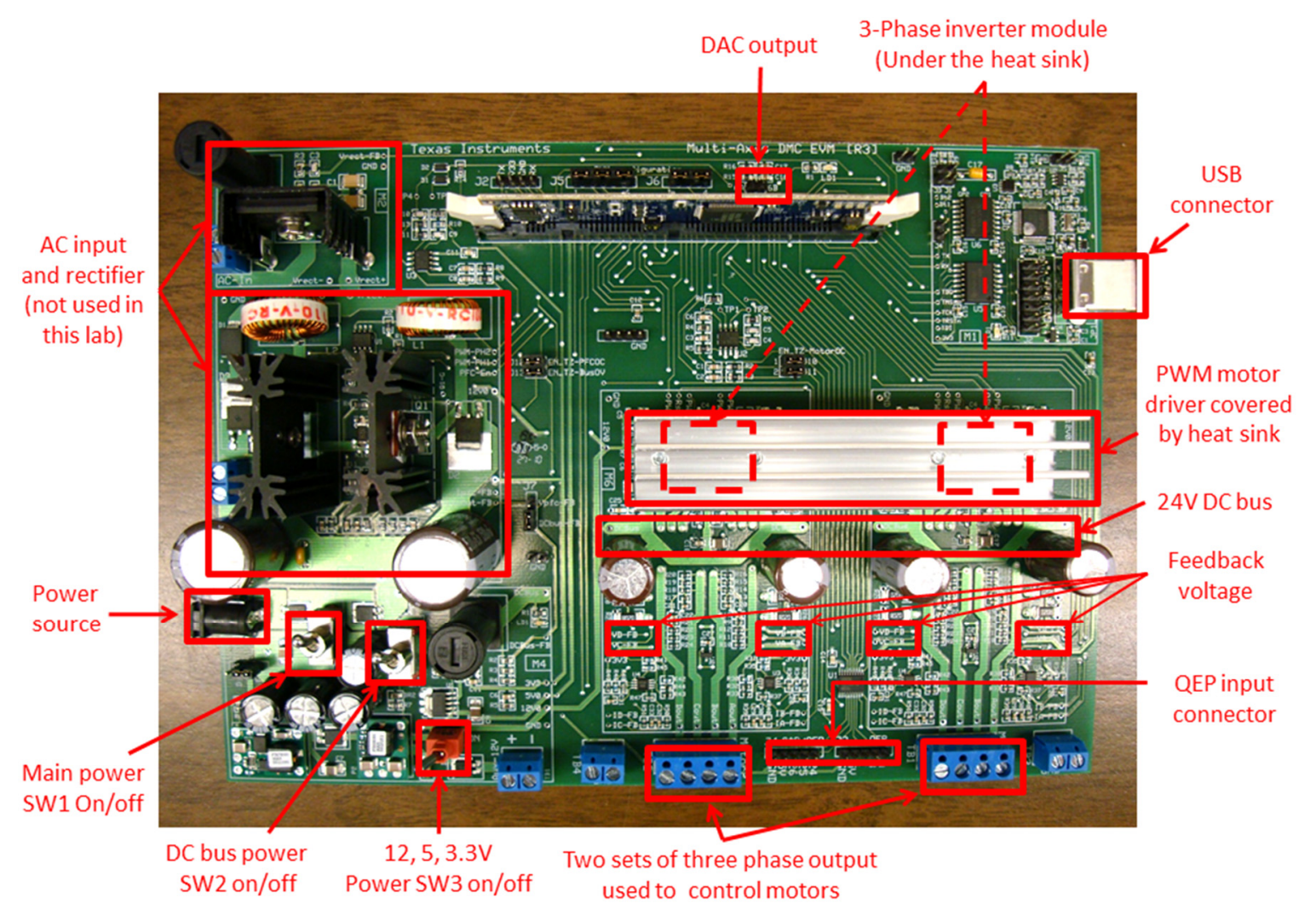

Figure 2: Dual motor control and power factor correction developer's kit from TI

\section{G. Academia-Industry Relationship}

Academia-Industry collaborations can be described as a win-win relationship where both partners benefit from each other's resources. Some of the advantages brought about from collaboration between industry and academia include giving students an opportunity to work on real world industrial equipment. This helps establish a curricula that improves the marketability of graduating students as the need for power industry workers grow ${ }^{16}$. An analysis from the Center for Energy Workforce Development warns of an impending crisis due to the upcoming retiring workforce in the power and energy field ${ }^{17}$. The combined efforts of educators and industry must work together to bridge this gap. For the industry perspective, the students they hire require less time to be trained, which reduces the learning curve and enables them to fill more crucial roles within the business.

The industrial support provided to the ECE at OSU, has not only significantly improved the number and diversity of sponsored research projects ${ }^{18}$, but has also had a major impact on the undergraduate and graduate education laboratories. New, modern lab spaces, with redesigned 
curriculum have been created to transform the way undergraduate and graduate students are being taught in laboratory courses. The goal is to introduce undergraduate students to advanced concepts early and empower them to become self-guided learners via state-of-the art equipment, video instruction, and carefully designed lab manuals. "Calling the ECE-approach a game changer in undergraduate education," TI partnered with the ECE at OSU and provided $\$ 160,000$ to support the effort ${ }^{19}$."

A new laboratory classroom was created and lab courses in analog and digital electronics, microcontrollers, power electronics and motor drives were all redesigned. The space includes 39 lab benches, each with similar equipment utilized in industry, including:

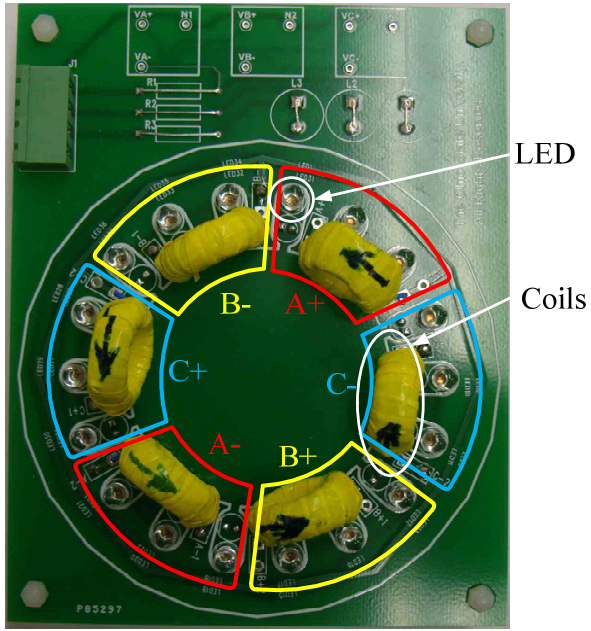

Figure 3: Three phase LED load.

- Agilent (MSO-X2014 A) oscilloscopes

- Rigol (DP1308) power supplies

- Rigol (DG1022A) signal generators

- iPads (A1397) that provide step-by-step instructional videos and custom lab materials.

\section{ASSESSMENT AND FEEDBACK}

In order to evaluate the effectiveness of the course objectives and how beneficial the lab experience was, two metrics were used. First, enrollment into the course over the last ten years was examined, and second, students were surveyed at the end of the semester.

\section{A. Student Enrollment}

Figure 4 shows the student enrollment history for the Power Electronics and Motor Drives Laboratory over the past ten years. As displayed, the number of students enrolled in the laboratory course doubled once the proposed lab was offered. Since this introduction of this class coincided with OSU's movement to a semester calendar, it is difficult to quantify an increase interest in this area. However, using the new open spaces approach, an instructor can now accommodate a classroom size of 30 students versus 12 before. 


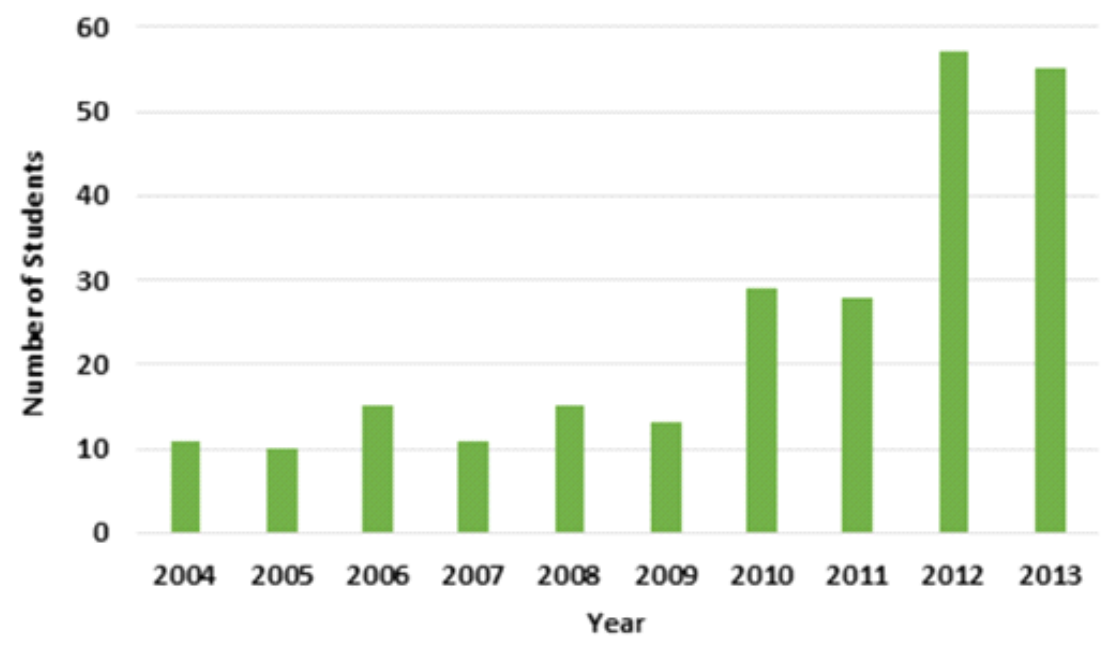

Figure 4: Student enrollment history for the power electronics and motor drives laboratory

B. Student Survey

In order to evaluate the effectiveness of the course objectives and how beneficial the lab experience was, students were surveyed at the end of the semester. Twenty-one out of twentyfour students in the class from different areas of specialization returned the survey. Nine of them were undergraduate (seniors) students and twelve are graduate students. Their areas of specialization are shown in Figure 5.

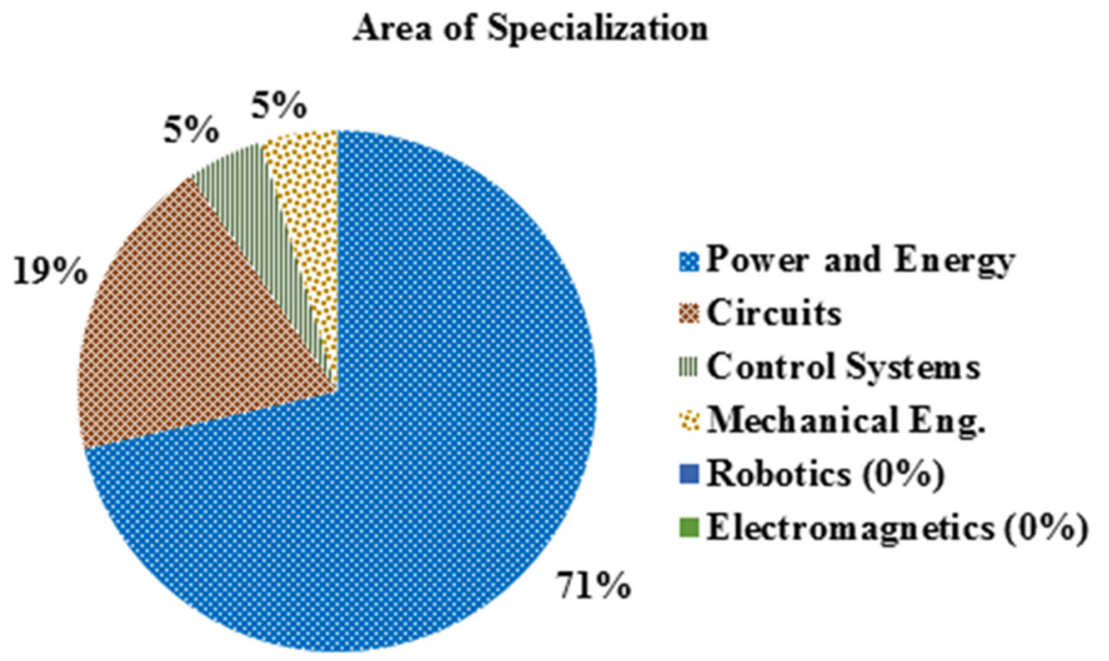

Figure 5: Survey Students’ Background Breakdown

The survey assesses the effectiveness of the "open space" structure of the lab. First, Students were asked two Yes/No questions. 
1. Is this your first "open space" lab?

2. If NO, have you previously taken a laboratory class that was not "open space?

Then, they were asked two multiple choice questions:

1. When do you usually watch the video lesson?

2. Are the video lessons clear and easy to understand?

Second, the survey instructs the students to read a series of statements and rate them on a scale from 1 to 5, with 5 indicating they strongly agree, and 1 indicating they strongly disagree with the statement. Table 2 shows the questions and their results.

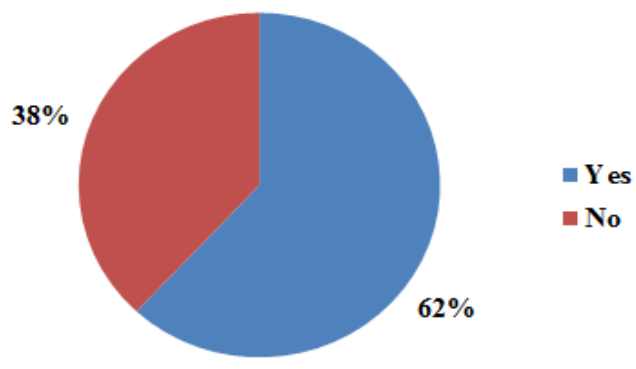

When do students usually watch the video lesson?

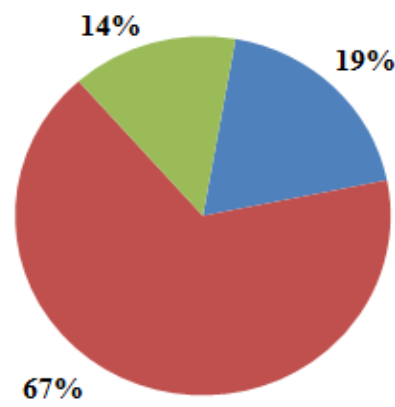

A day or two before the class

- Right before the class

In class is the first time I see the video

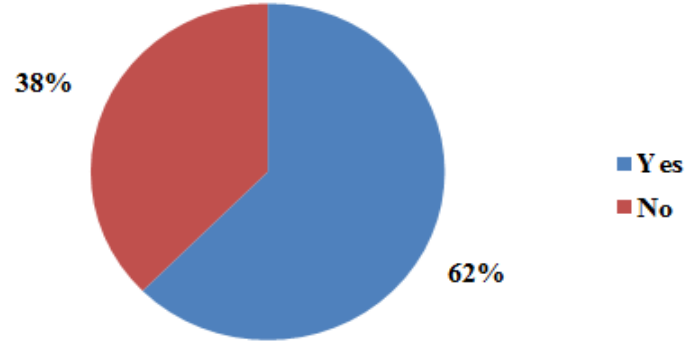

How Do Students Prefer to Work? $10 \%$

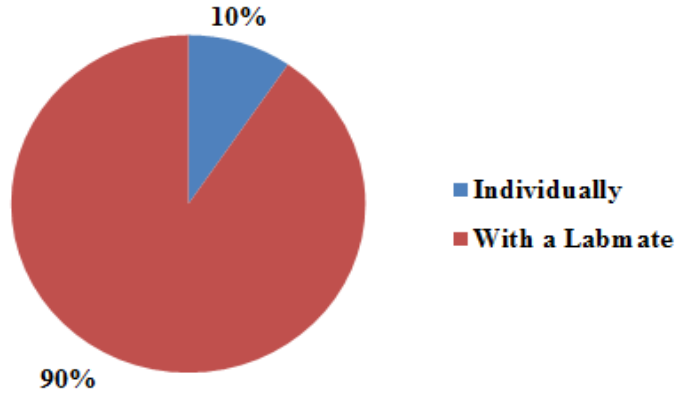

Figure 6: Student responses to the survey Yes/No and multiple-choice questions

Figure 7 compares the average of students' response to questions 1, 2, 5, 6 and 8, listed in table 2 , based on their area of specialization. The analysis of figure 3 shows the following results:

- In reply to questions $1 \& 5$, students from different areas of specialization found that the material of the lab is well prepared and organized and can be understood regardless of 
their background. On the other hand, students from the power and energy area found that the experiments were easy to setup and perform compared to other students since they had more experience from other similar courses and laboratories.

- Question 2 shows that the open space environment was helpful and students learned a lot by using this teaching approach.

- In response to questions $6 \& 8$, students from the different areas of specialization, including power and energy, felt that this lab experience was beneficial to their future career goals, since power electronics has many applications in different career paths. The laboratory also increased the interest of students from other areas of specialization, to pursue a career in power electronics.

Third, students were asked two additional optional questions:

1. Which type of lab environment do you prefer: OPEN SPACE or CLOSED SPACE. Why?

2. List two aspects of the "open space" laboratory class that you would change.

In response to question one, $90 \%$ of students selected the Open Space environment. They explained that the open space teaching methodology is more efficient, interactive and enjoyable than the closed space approach. It helps students to understand the laboratory objectives and finish the required task quickly since they have the opportunity to watch the lab videos either before or during the lab hours. It also gives students the opportunity to improve their hands-on experience to design, control and debug power electronic circuits and as well as applying them to motor drives.

In reply to question two, $60 \%$ of students requested adding a few free lab periods to the laboratory course where they can have the opportunity to practice alone without being guided by a lab procedure. Other suggestions were:

- They prefer to have additional challenging problems with an additional extra credit where they can improve their debugging skills.

- They recommended having an optional recitation class during the week where students can ask questions.

\section{Future Work}

Students' comments and suggestions are being considered in the future work plan of the Power Electronics and Motor Drives Laboratory at OSU such that they can be integrated with the current developed lab. The proposed future work plan consists of two parts: a short-term part that will be available the next time the course is offered to students and a long-term part that depends on the available industrial support. The short-term future work plan includes: 
1- In regards to the students' preference to have additional challenging problems with extra credits, a final design project will be added to the curricula of the lab where students will combine all of their class and laboratory work. The project is based on their knowledge of power electronics, motor control, system modeling and analysis and performance measurements and analysis.

2- In reply to the students' suggestion of an optional recitation class during the week where students can ask questions, an additional teaching assistant with fixed office hours will be added to the teaching team. Then he/she can answer any question or solve any problems. Also, an additional discussion forum will be added to the course home page such that students can chat with each other and with the teaching assistant and share their questions, ideas, observations and notes.

The long-term future work plan includes integrating the real-time simulation (RTS) platform, available at OSU, into the laboratory curricula. This provides students with an enhanced and interactive learning environment that serves as a bridge from theory to practice and from passive learning to active engagement while not being limited by the finite resources of laboratory hardware and software.

As the system complexity increases, the amount of time needed to simulate also increases, and depending on the complexity of the system, the time cost of simulation can be very expensive; this is especially true for $\mathrm{AC}$ motor drives with switching power electronics. Increased time consumption is exacerbated by the limited flexibility when changes in the realized prototype are brought about by changes in the design.

RTS can mimic a complex model with the advantage of design or parameter changes done in real time. It can lower costs by allowing for faster design development and costs can be further reduced by incorporating hardware-in-the-loop (HIL) or system-in-the-loop (SITL) simulations.

\section{CONCLUSIONS}

Educators of PEMC need to be creative when developing curriculum to teach the next generation of engineers. Courses must be efficiently organized to cover a diverse group of subjects. Hardware is expensive, and experiments dangerous; thus an innovative approach is required to build relevant lab setups that are safe, simple, and easily accessible.

These factors were taken into consideration while the ECE at OSU created its Power Electronics and Machine Control Laboratory. Following trends such as constructing hardware for the experiments, and working with a partner in industry, (TI); The "Open Space Laboratory" was introduced to ECE students. This paper presented details related to the implementation of this approach, the hardware that was used, and the curriculum that was covered. 
Student assessments show that they felt that they learned a significant amount of material in the course. They feel better prepared for an interview as a result, and several are even considering pursuing a career in power electronics as a result of this course. The structure and content of this lab will continue to evolve as the needs of students and industry employers change. Alterations to format and style of the lab's implementation will be presented in future publications.

Table 2: Student survey with the results.

\begin{tabular}{|l|l|ccccc|c|}
\hline & Question & $\mathbf{5}$ & $\mathbf{4}$ & $\mathbf{3}$ & $\mathbf{2}$ & $\mathbf{1}$ & Avg. \\
\hline 1 & The material of the lab is well organized & 15 & 6 & 0 & 0 & 0 & 4.71 \\
\hline 2 & I feel that I learned a lot as a result of the open space lab environment & 13 & 8 & 0 & 0 & 0 & 4.62 \\
\hline 3 & $\begin{array}{l}\text { I prefer the open space lab environment to the traditional lecture based } \\
\text { approach }\end{array}$ & 14 & 4 & 2 & 0 & 1 & 4.38 \\
\hline 4 & $\begin{array}{l}\text { I would prefer a live lecture as opposed to having the video's available } \\
\text { online }\end{array}$ & 5 & 2 & 7 & 5 & 2 & 3.14 \\
\hline 5 & $\begin{array}{l}\text { The experiments were easy to setup and perform } \\
6\end{array}$ & $\begin{array}{l}\text { I feel that this lab experience was beneficial to my future career goals } \\
7\end{array}$ & 12 & 4 & 0 & 0 & 4.05 \\
\hline 8 & $\begin{array}{l}\text { I feel better prepared for interviews as a result of this lab experience } \\
\text { electronics }\end{array}$ & 9 & 7 & 4 & 1 & 0 & 4.14 \\
\hline 9 & I would recommend an open space lab to a colleague & 7 & 9 & 4 & 1 & 0 & 4.05 \\
\hline
\end{tabular}

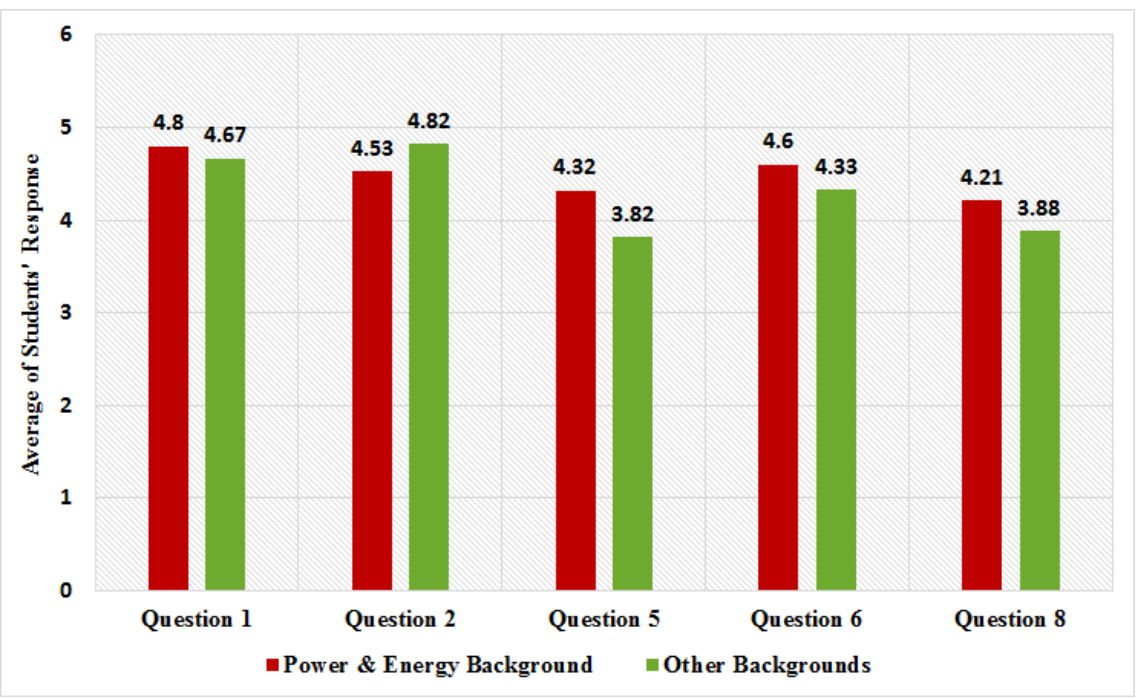

Figure 7: Comparison of student responses to questions 1, 2, 5, 6, and 8 based on their area of specialization 


\section{REFERENCES}

1 P. Patel, “Where the jobs are: 2012”, IEEE Spectrum, vol. 49, no. 9, pp. 26, Sept. 2012.

2 V.G. Agelidis, "The future of power electronics-power engineering education: challenges and opportunities", IEEE Workshop on Power Electronics Education, 2005, Mar Hotel Recife, Brazil, June 16-17, 2005, pp.1-8.

3 M.D. Koretsky, D. Amatore, C. Barnes, S. Kimura, "Enhancement of Student Learning in Experimental Design Using a Virtual Laboratory", IEEE Transactions on Education, vol. 51, no.1, pp.76 - 85, Feb. 2008.

4 W. Robbins, N. Mohan, P. Jose, T. Begalke, C. Henze, T. Undeland, "A building-block-based power electronics instructional laboratory," IEEE 33rd Annual Power Electronics Specialists Conference (PESC), 2002, Cairns, Queensland, Australia, June 24-27, 2005, pp.467 - 472.

5 N. Mohan, W.P. Robbins, P. Imbertson, T.M. Undeland, R.C. Panaitescu, A.K. Jain, P. Jose, T. Begalke, "Restructuring of first courses in power electronics and electric drives that integrates digital control", IEEE Transactions on Power Electronics, vol.18, no.1, pp. 429 - 437, Jan. 2003.

${ }^{6}$ R.S. Balog, Z. Sorchini, J.W. Kimball, P. L. Chapman, P. T. Krein, P. W. Sauer, "Blue-box approach to power electronics and machines educational laboratories", IEEE Power Engineering Society General Meeting, 2005, San Francisco, CA, June 12-16, 2005, pp. $1176-1184$.

7 R.S. Balog, Z. Sorchini, J.W. Kimball, P. L. Chapman, P. T. Krein, P. W. Sauer, "Modern laboratory-based education for power electronics and electric machines", IEEE Transactions on Power Systems, vol. 20, no. 2, pp. 538 - 547, May 2005.

8 S. Anand, R. Singh, F.B.G Fernandes, "Unique Power Electronics and Drives Experimental Bench (PEDEB) to Facilitate Learning and Research", IEEE Transactions on Education, vol. 55, no. 4, pp.573 - 579, Nov. 2012.

9 F.J.C. Padilha, W.I. Suemitsu, L.G.B. Rolim, G.G. Sotelo, "A modular power electronics protoboard for didactic applications", Power Electronics Conference (COBEP '09), 2009, Bonito-Mato Grosso do Sul, Brazilian, Sept. 27 - Oct. 1 2009, pp.1099 - 1103.

${ }^{10}$ W.G. Hurley, C.K. Lee, "Development, Implementation, and Assessment of a Web-Based Power Electronics Laboratory", IEEE Transaction on Education, vol. 48, no. 4, pp. 567-573, Nov. 2005.

${ }^{11}$ Manisha, M. Manuja, "Industry academia collaboration model: The design challenges", IEEE $24^{\text {th }}$ Annual Conference on Software Engineering Education and Training (CSEE\&T), Honolulu, HI, May 22 - 24, 2011, pp. $111-120$.

${ }^{12}$ E. Collines, "An energy conversion laboratory using industrial-grade equipment", IEEE Transactions on Power Systems, vol. 24, no. 1, pp. 3 - 11, Feb. 2009.

${ }^{13}$ A.P.A Salazar, M. Cabrera-Rios, "Building bridges between academia and industry for industrial and systems engineering in Latin American", Latin American and Caribbean Journal of Engineering Educations, vol. 5, no. 1, pp. $7-11,2011$

${ }^{14}$ P.M. Menghal, A.J. Laxmi, "Real time simulation: A novel approach in engineering education", 3rd International Conference on Electronics Computer Technology (ICECT), 2011, Kanyakumari, Tamil Nadu, India, April 8 - 10, 2011 , pp. $215-219$. 
${ }^{15}$ C. Dufour, C. Andrade, J. Belander, "Real-time simulation technologies in education: A link to modern engineering methods and practices", $11^{\text {th }}$ International Conference on Engineering and Technology Education (INTERTECH), Ilheus, Bahia, Brazil, Mar. 7 - 10, 2010, pp. 15.

${ }^{16}$ A. Sergeyev and N. Alaraje, "Industry-Driven Power Engineering Curriculum Development in Electrical and Computer Engineering Technology Program," 2011 ASEE Conf. \& Expo, paper AC 2011-953, Vancouver, Canada.

${ }^{17}$ Center for Energy Workforce Development, "Gaps in the Energy Workforce Pipeline - 20011 Survey,” 20011, available at: http://www.cewd.org/

${ }^{18}$ The Ohio State University, College of Engineering, "2012 Annual Statistical Report", The Ohio State University, College of Engineering, Columbus, Ohio,

[Online.] Available: http://engineering.osu.edu/about/faculty-and-staff/administrative/annual-report

${ }^{19}$ The Ohio State University, Electrical \& Computer Engineering Department, "2011-2012 Annual Statistical Report", The Ohio State University, Columbus, Ohio,

[Online.] Available: https://ece.osu.edu/sites/ece.web.engadmin.ohio-state.edu/files/uploads/publications 